\title{
Calcium Sulfate Crystals Measurement
}

National Cancer Institute

\section{Source}

National Cancer Institute. Calcium Sulfate Crystals Measurement. NCI Thesaurus. Code C124340.

The determination of the amount of calcium sulphate crystals present in a sample. 